Revista Eletrônica em Gestão, Educação e Tecnologia Ambiental

Santa Maria, v. 20, n. 1, jan.-abr. 2016, p. 334-350

Revista do Centro de Ciências Naturais e Exatas - UFSM

ISSN : 22361170

\title{
Consciência e Atitude Ambiental em Estudantes de Instituições de Ensino Técnico e Tecnológico
}

\author{
Linnik Israel Lima Teixeira ${ }^{1}$, José Carlos Lázaro Silva Filho² e \\ Fernanda Rosalina da Silva Meireles ${ }^{3}$ \\ ${ }^{1}$ Coordenador de Assuntos Estudantis da Universidade Federal do Ceará , Brasil \\ 2Doutor, Professor Adjunto da Universidade Federal do Ceará , Brasil \\ ${ }^{3}$ Mestre,Técnico Administrativo do Instituto Federal do Ceará - Reitoria , Brasil
}

\begin{abstract}
Resumo
A educação ambiental é apontada como uma poderosa ferramenta de conscientização ambiental coletiva, desde o ensino básico até o nível superior. Com base nisso, o presente estudo tem como objetivo investigar a consciência ambiental e o comportamento ambiental entre universitários de uma instituição tecnológica de ensino. Usando a Escala NEP (DUNLAP et al., 2010) buscou-se examinar a relação entre consciência e comportamento ambiental por meio das variáveis curso, semestre, gênero e educação ambiental, através questionário aplicado com os estudantes. A análise dos dados, gerada após comparações entre médias de desempenho, pode ser dividida em dois resultados: a) da consciência ambiental, não foi observado diferenças significativas entre os cursos e também em relação aos semestres dos entrevistados. Por outro lado, foram constatados níveis significantemente maiores de consciência ambiental em mulheres e em universitários que estudaram educação ambiental antes de ingressar no ensino superior; b) do comportamento ambiental, as maiores médias de comportamento próambiental foram encontradas nos estudantes de Engenharia Ambiental, nos egressos, nas mulheres e nos universitários que estudaram educação ambiental antes de iniciar o ensino superior. Os resultados do estudo apresentam conformidade com outras pesquisas e sugerem a pesquisadores da área um aprofundamento dos fatores que influenciam esses resultados.
\end{abstract}

Palavras-chave: Educação Ambiental. Consciência Ambiental. Comportamento Ambiental.

\begin{abstract}
Environmental education is a powerful tool for forming collective environmental awareness from primary school to higher education level. Based on this, this study aims to investigate environmental awareness and environmental behavior among students of a technological educational institution. Using the NEP Scale (Dunlap et al., 2010) through a questionnaire with students it sought to examine the relationship between consciousness and environmental behavior through variables like course, semester, gender and environmental education. The final data generated can be divided into two outcomes: a) environmental awareness, was not observed significant differences between the courses and also for the semesters of respondents. On the other hand, significantly higher levels of environmental awareness were found in women and students who studied environmental education before they enter higher education; b) the environmental behaviour, the highest levels of pro-environmental behavior were found in students of Environmental Engineering, the graduates, on women and college students who studied environmental education before starting higher education. The study results show compliance with other research and suggest area researchers a deepening of the factors that influence these results.
\end{abstract}

Keywords: Environmental education. environmental awareness. environmental behavior.

linnik.lima@gmail.com

Recebido: 15/10/15 Aceito: 29/02/16 


\section{Introdução}

A percepção de que os recursos naturais são finitos e de que sua extinção ameaça a sobrevivência humana provocou repercussões políticas, sociais, econômicas e científicas. Desde o final da década de 1960, muitos foram os movimentos, conferências e compromissos realizados com o objetivo de respeitar o meio ambiente. (SILVA FILHO et al. 2009; NASCIMENTO; LEMOS; MELLO, 2008; SEIFFERT, 2007)

As discussões iniciais promovidas em encontros relacionavam-se à responsabilidade das esferas governamentais e empresariais na preservação ambiental. Com o avanço das discussões, o ser humano, como indivíduo, passou a ser incluído na responsabilidade de cuidar do meio ambiente. Para isso, muito importante tornava-se sua conscientização e seu envolvimento nos debates que apareciam. A Conferência de Estocolmo, em 1972, tornou-se um marco ao instrumentalizar uma poderosa ferramenta para conscientização do homem: a Educação Ambiental (EA). De acordo com Barbieri e Silva (2011), após a Conferência de Estocolmo, a EA passa a gozar de especial atenção nos fóruns subsequentes sobre desenvolvimento econômico e meio ambiente.

Paralelamente, no contexto empresarial, as organizações perceberam que as ações sustentáveis são uma realidade eminente, frente à conscientização crescente dos cidadãos diante de questões ambientais (MAZZA et al., 2011). Em resultado, o mercado passou a demandar cada vez mais profissionais com formação na área ambiental.

A convergência desses acontecimentos resultou na inserção e desenvolvimento da sustentabilidade no contexto educacional. Atualmente, é notório o espaço que a sustentabilidade vem conquistando no campo educacional e a inclusão da sustentabilidade nos currículos educacionais é tema de ampla discussão. De acordo com Vehzke e Nascimento (2013), o cerne dessas discussões consiste em definir o grau de atuação dos sistemas educacionais na geração de conhecimento relacionado ao tema, assim como o incentivo a ações sustentáveis e formulações de caráter estratégico para possibilitar esse tipo de sustentabilidade.

Uma das discussões acadêmicas de repercussão envolve a conscientização ambiental. De acordo Diamantopoulos et al. (2003), nos últimos 25 anos, numerosas pesquisas nas áreas de Ciências Sociais foram desenvolvidas com o objetivo de conceituar e operacionalizar o construto da consciência ambiental.

No Brasil, a incorporação das questões ambientais na educação deu-se de forma tardia. Somente em 1999 foi promulgada a lei que estabelece a Política Nacional de Educação Ambiental, a Lei no 9.795, que estabelece a obrigatoriedade do ensino de educação ambiental na educação básica, intermediária e superior. No ano seguinte, surge o primeiro curso de graduação em Gestão Ambiental no Brasil, e rapidamente surgem muitos cursos superiores voltados para questões ambientais, ecológicas e sustentáveis (DEMAJOROVIC; SILVA, 2012).

A formação acadêmica tem efeito direto na atuação profissional; quanto ao aspecto pessoal, não se pode afirmar isso, visto que a consciência e o comportamento ambiental são fatores que transcendem os conteúdos vistos em sala de aula. Diante disso, surgiu como problema de pesquisa a investigação do nível de consciência e comportamento ambiental entre estudantes universitários e a possível influência do curso nesses aspectos.

O presente estudo torna-se relevante à medida que revela o perfil de profissionais que entram atualmente no mercado e estabelece reflexão sobre o conteúdo adquirido em sala e a ação na vida cotidiana. Esta pesquisa complementa estudos e auxilia discussões no que se refere à importância das disciplinas de temática ambiental na formação do indivíduo com consciência e comportamento ecológicos. 


\section{Referencial Teórico}

\subsection{Sustentabilidade}

A preocupação com o meio ambiente tem sua origem em movimentos ambientalistas que começaram a se formar em meados do século XIX, durante a expansão da industrialização e seus efeitos no meio ambiente, que provocou o aparecimento de iniciativas científicas e artísticas em prol da criação de áreas de proteção humana (BARBIERI; CAJAZEIRA, 2009).

O destaque do assunto a nível mundial ocorre a partir da década de 1950, com degradação ambiental crescendo aceleradamente, em resultado das operações dos processos industriais e dos acidentes ambientais de grandes proporções, causando queda da qualidade de vida em algumas regiões de planeta (NASCIMENTO; LEMOS; MELLO, 2008; SEIFFERT, 2007).

Em 1962, o lançamento do livro Silent Spring ("Primavera Silenciosa"), de Raquel Carson, torna-se um marco na literatura ambiental. A obra estabelece interconexões entre meio ambiente, economia e bem-estar social (NASCIMENTO, 2012). No final dos anos 1960, é criado o Clube de Roma, que elabora um relatório intitulado Limits to Growth ("Limites do Crescimento"), alertando para as consequências da manutenção do desenvolvimento econômico existente, projetando para cem anos o esgotamento dos recursos naturais essenciais do planeta (FRANCO, 2008). Este relatório influenciou diretamente na organização da Conferência das Nações Unidas para o Meio Ambiente e Desenvolvimento (NASCIMENTO, 2012).

Em 1972 ocorre a Conferência das Nações Unidas para o Meio Ambiente, em Estocolmo, Suécia, que firma as bases para um novo entendimento a respeito das relações entre o meio ambiente e o desenvolvimento (BARBIERI, 2007). O encontro representou a primeira iniciativa dos governos mundiais em discutir os impactos econômicos no meio ambiente (SEIFFERT, 2007). As discussões geradas na conferência resultaram na criação da Declaração da Conferência das Nações Unidas sobre o Meio Ambiente Humano.

No mesmo ano, a ONU cria o Programa das Nações Unidas para o Meio Ambiente (PNUMA), uma agência que tem como finalidade monitorar o meio ambiente global, alertar os povos sobre práticas de risco ao meio ambiente e recomendar medidas para melhoria da qualidade da população, resguardando as gerações futuras (ONU, 2013).

A década de 1980 tem como marco o relatório da Comissão Mundial sobre o Meio Ambiente e Desenvolvimento (CNUMAD), da ONU, intitulado "Nosso Futuro Comum", ou Relatório de Brundtland. O relatório destaca a preocupação com a acelerada degradação ambiental, afirmando que essa ameaça chega a ser até mesmo maior que países fortemente armados e mal-intencionados (ONU, 1991). No final dessa década, ocorre mais um avanço contra a poluição ambiental: é firmado o Protocolo de Montreal, que extingue o uso de clorofluorcarbonos e estabelece prazos para sua substituição.

Na década de 1990, a definição de Desenvolvimento Sustentável é consolidada por meio da Conferência Mundial de Desenvolvimento e Meio Ambiente, sediada no Rio de Janeiro, e mais conhecida como ECO-92 ou RIO-92. A conferência aprovou vários documentos, incluindo convenções, declarações de princípios e o seu trabalho mais conhecido: A Agenda 21(BARBIERI, 2007).

Em 1997, ocorre em a 6 a Conferência das Partes das Nações Unidas sobre Mudanças Climáticas, onde são discutidas providências a serem tomadas em relação ao aquecimento global. Em resultado, foi produzido o Protocolo de Kyoto, que estabeleceu metas de redução de emissões de gases que contribuem para o aquecimento global até 2012, em relação aos emitidos na década de 1990.

De modo geral, Nascimento (2012) afirma que a década de 90 caracterizou-se pela preocupação com o processo produtivo e a redução de desperdício de matéria-prima renovável e não-renovável. Neste sentido, o autor destaca o aparecimento da qualidade ambiental, operacionalizada por meio das certificações ambientais, e o surgimento de uma preocupação das organizações em manter uma imagem de empresa ambientalmente correta. 
A adaptação das empresas diante do novo conceito de sustentabilidade criou a necessidade de profissionais especializados em tais áreas. Além disso, as conferências mundiais já destacavam o papel da educação como ferramenta transformadora e essencial para a formação do novo paradigma do desenvolvimento sustentável.

\subsection{Educação Ambiental}

A história da Educação Ambiental (EA) está implicitamente relacionada à própria história da sustentabilidade. Para Loures (2009) e Marinho (2004), as primeiras incursões de uma educação pautada na sustentabilidade ocorrem na segunda metade do século XIX, com o lançamento do livro "O homem e a natureza: ou geografia física modificada pela ação do homem", de George Perkin Marsh. No livro, o autor fazia previsão do esgotamento dos recursos naturais e demonstrava angústia diante da ação devastadora do homem (MARINHO, 2004).

Já a expressão "Educação Ambiental" (Enviromental Education) é usada pela primeira vez em 1965, em Londres, durante a Conferência de Educação da Universidade de Keele, onde foi destacada a essencialidade dessa abordagem na vida de todos os cidadãos (LOURES, 2009; NASCIMENTO; LEMOS; MELLO, 2008). Barbieri e Silva (2011), por sua vez, comentam que as origens da EA se confundem com as próprias origens da Organização das Nações Unidas para a Educação, a Ciência e a Cultura (UNESCO). Desde sua criação, o órgão promoveu diversas iniciativas de debate sobre a EA, mobilizando os governos e setores da sociedade civil.

Após a Conferência de Estocolmo, em 1972, a EA passou a receber especial atenção da grande maioria dos fóruns relacionados com a temática do desenvolvimento e meio ambiente. No mesmo ano, com a criação da PNUMA, Barbieri e Silva (2011) afirmam que a UNESCO passou a dividir com esse programa as questões relativas à EA, no âmbito das Nações Unidas. Como resultado da parceria, foi criado um plano de trabalho com 110 resoluções que abordam, dentre outros, a Educação Ambiental e a necessidade de implantá-la com caráter interdisciplinar.

Para o cumprimento das recomendações, a UNESCO e o PNUMA criam o Programa Internacional de Educação Ambiental (PIEA), em 1975. A primeira grande atividade do PIEA foi a organização do Seminário Internacional de Educação Ambiental, ocorrida em Belgrado, que resultou na edição da Carta de Belgrado. A carta destaca que a meta da Educação Ambiental é a formação de uma população mundial consciente e preocupada com o meio ambiente e com os problemas relacionados (BARBIERI; SILVA, 2011).

Em 1977, a Conferência Internacional de Tbilisi, na URSS (atualmente Geórgia), ratificou diversos conceitos adotados na Carta de Belgrado e modificou outros. Recomendou-se que os programas de EA tenham enfoque pluridisciplinar, centralizados na solução de problemas e nos sistemas de equipes multidisciplinares integradas (BARBIERI; SILVA, 2011). No total, o evento produziu 41 recomendações acerca da EA.

Após dez anos, ocorreu em Moscou o Congresso Internacional sobre a Educação e Formação relativas ao Meio Ambiente, promovido pela UNESCO. O documento final, o Relatório de Brundtland, destaca o papel da educação na preservação ambiental. A inserção de disciplinas sobre o meio ambiente é vista como essencial, pois a educação convencional não tem sido suficiente para orientar e estimular as pessoas a aprimorar práticas de produção e proteger melhor os recursos naturais (ONU, 1991).

Em 1992, surge a Agenda 21, documento produzido durante a ECO-92, que dedica o capítulo 36 à promoção do ensino, da conscientização e do treinamento (ONU, 1995). Para acompanhar e avaliar a implantação das recomendações propostas na Agenda 21, foi criada, ainda em 1992, a Comissão de Desenvolvimento Sustentável (CDS).

Dez anos após o encontro do RIO-92, ocorre a Cúpula Mundial sobre Desenvolvimento Sustentável, em Johannesburgo, África do Sul. Conhecido também pelo nome de Rio+10, o evento produziu 153 recomendações para o cumprimento efetivo da Agenda 21, que não contemplavam diretamente os aspectos da EA (BARBIERI; SILVA, 2011). Em 2003, como consequência do Rio+10, o decênio de 2005-2014 foi proclamado a Década das Nações Unidas da Educação para o Desenvolvimento Sustentável. Os objetivos dessa década são a valorização do papel da educação e

REGET - V. 20, n. 1, jan.- abr. 2016, p.334-350 
aprendizado no desenvolvimento sustentável; promover o conceito de desenvolvimento sustentável; e incentivar a melhoria da qualidade do ensino no âmbito da educação para o desenvolvimento sustentável (UNESCO, 2005).

\subsubsection{Educação Ambiental nas Instituições de Ensino Superior}

Apesar da discussão sobre a educação ambiental ocorrer há décadas, apenas na década de 1990 observou-se um crescimento na adesão das instituições de nível superior no mundo com o comprometimento com a sustentabilidade (JACOBI; RAUFFLET; ARRUDA, 2011).

No Brasil, a edição da Lei 9.795/99, que estabelece as políticas de educação ambiental do país, traz um marco histórico desse tema na educação brasileira. Sem dúvida, os eventos internacionais, especialmente o RIO-92, tiveram influência direta para a produção da lei, visto que constituía um dos objetivos da Agenda 21.

A lei inicia com uma definição de educação ambiental:

Entendem-se por educação ambiental os processos por meios dos quais o indivíduo e a coletividade constroem valores sociais, conhecimentos, habilidades, atitudes e competências voltadas para a conservação do meio ambiente, bem de uso comum do povo, essencial à sadia qualidade de vida e sustentabilidade (BRASIL, 1999, p.1).

Nos aspectos relacionados à educação formal, a lei explica que sua implantação deverá ocorrer em todos os níveis, incorporada de forma transversal nas variadas disciplinas (BRASIL, 1999). Sobre a transversalidade do ensino ambiental, Jacobi, Raufflet e Arruda (2011) apontam que experiências internacionais nas instituições de ensino superior têm demonstrado que estas têm dado enfoque fragmentado à sustentabilidade, demonstrando uma visão reducionista da educação por parte dos professores.

Não obstante às dificuldades de implantar a educação ambiental nas instituições de ensino superior, é notável observar, após a edição da Lei 9.795/99, o crescimento de cursos superiores voltados para a área ambiental. De acordo com Demajorovic e Silva (2012), mais de 191 cursos foram contabilizados até o penúltimo censo da educação superior, realizado em 2008. No entanto, os autores alertam que o crescimento desses cursos superiores suscita questionamentos: a falta de interdisciplinaridade observada nos cursos de graduação, assim como o efeito que esses novos cursos emergentes estão tendo sobre a conscientização de seus universitários.

Estudos que investigam a influência dos cursos de graduação relacionados à sustentabilidade ainda são incipientes. Por outro lado, é positivo destacar que a pesquisa relacionada ao tema sustentabilidade tem sido crescente no Brasil. Uma análise bibliométrica realizada por Souza et al. (2011), durante os anos de 2000 a 2010, em que pesquisaram as publicações relacionadas à sustentabilidade nas revistas científicas de administração com Qualis A1 a B2, concluiu que houve um aumento significativo na produção científica, o que indica amadurecimento da área no período.

Existem muitas formas de investigar o impacto de tais cursos superiores nos universitários. Das muitas maneiras que a Educação Ambiental atua nas pessoas, destaca-se a consciência ambiental. A abordagem a seguir conceitua a consciência ambiental e suas relações com o campo educacional.

\subsection{Consciência e Comportamento Ambiental}

As questões ambientais estão atualmente em pautas de destaque na mídia, sendo transmitidas de forma massiva à sociedade. Dias (2008) destaca que essa tendência tende a aumentar à medida que os problemas ambientais do planeta se agravam.

A conscientização ambiental pode ser entendida como uma mudança de comportamento em relação ao meio ambiente, expressa nos diversos contextos de um indivíduo (BUTZKE; PEREIRA; NOEBAUR, 2001). Dessa forma, aqueles que possuem maiores níveis de consciência ambiental têm 
mais tendência de tomar suas decisões levando em conta seus impactos no meio ambiente (BEDANTE; SLONGO, 2004).

A definição dada de consciência ambiental deixa evidente a relação existente entre a consciência ambiental e comportamento ambiental: enquanto que a consciência ambiental é mais abrangente, envolvendo caraterísticas intrínsecas do indivíduo, o comportamento ambiental, por sua vez, trata-se da manifestação ativa da consciência.

A consciência e o comportamento ambiental tem sido tema de diversas pesquisas. O objetivo de tais levantamentos é tentar descobrir características que influenciam ou indiquem tendências de consciência ambiental a determinados tipos de pessoas. No marketing, estudos buscam traçar o perfil de consumidores com consciência ambiental a partir do seu comportamento como consumidor. Por exemplo, a Organização Roper (1992 apud Battistela et al., 2012), realizou um estudo em 1992, em que encontro evidências de que os consumidores mais conscientes tendem a ser mais educados, ganhar mais dinheiro e ser do sexo feminino. Vinte anos depois, a organização repete o estudo e indica que a geração Y (nascidos entre 1978-1990) demonstra grande interesse no meio ambiente e são mais engajados nas causas ambientais (ROPER, 2011).

Pesquisas na área do marketing indicaram que fatores demográficos têm tido sucesso limitado quanto a descobrir perfis de consumidores com determinada consciência ambiental (SCHLEGELMILCH; BOHLEN; DIAMANTOPOULOS, 1996). Outros estudos tentam associar a consciência e o comportamento ecológico à educação ambiental. Uzzell et al. (1995 apud Rickinson, 2001) investigou o efeito de quatro dias de curso de educação ambiental em um público jovem na Inglaterra. Os jovens foram avaliados sobre sua percepção ambiental antes, após o curso e seis semanas depois. O resultado indicou que eles obtiveram um significante aumento de seu entendimento sobre os problemas ambientais a nível local e nacional depois de feito o curso. Chawla e Cushing (2007) defendem que a educação ambiental pode influenciar os estudantes a ganhar mais conhecimento e a ter atitude mais positiva sobre o ambiente e assim agir na prática.

Como já exposto anteriormente, a EA é apontada exaustivamente como fator de conscientização ambiental. A Lei 9.795/99 destaca que um dos objetivos de educação ambiental é o estímulo e fortalecimento de uma consciência crítica sobre os problemas ambientais e sociais. Por isso, é essencial que a abordagem de assuntos relacionados à sustentabilidade seja iniciada desde a educação básica. No ensino superior, existem os cursos com relação direta com o desenvolvimento sustentável e outros com relação indireta.

Atualmente, o site Ministério da Educação (2013) aponta quase 700 cursos superiores cujo título relaciona-se ao termo "ambiental". Um destaque é o número de cursos de engenharias, que somam quase 300, sob diferentes nomes, como "engenharia agrícola e ambiental", "engenharia ambiental", "engenharia ambiental e sanitária", dentre outros.

\subsubsection{O Novo Paradigma Ecológico e a Medida da Consciência Ambiental}

O contexto dos anos 70 indicava a necessidade de mudança de paradigma, o que foi sentido por diversos autores (SILVA FILHO et al., 2009). A emergência de mudança de paradigma deu oportunidade aos humanos de reconhecerem que possuem limitações e interdependências ecológicas, mesmo com a sua capacidade de modificar o ambiente (LIMA, 2009). Assim, o Novo Paradigma Ecológico se assenta na ideia de dependência ecológica da sociedade humana e as insere na complexa rede de relações interdependentes do ecossistema. Silva Filho et al. (2009) comenta que, enquanto muitos atores ficaram na proposição da existência do novo paradigma, outros buscaram um instrumento para medi-lo.

Foi nesse contexto que os pesquisadores Dunlap e Van Liere criaram, em 1978, a Escala do Novo Paradigma Ambiental (NEP), que contrapõe os conceitos adotados pelo antigo paradigma (PSD), e visa medir a aderência das pessoas ao novo paradigma. A Escala NEP baseou-se em três dimensões: I - A capacidade humana de perturbar o equilíbrio natural; II - A existência de limites ao crescimento; e III - O direito do homem de reinar sobre a natureza.

A Escala NEP possuía doze itens, sendo oito pró e quatro contra o novo paradigma, com uma escala Likert de quatro pontos (discordo fortemente até concordo fortemente). Pontuações mais altas 
na escala indicam uma visão ecocêntrica, comprometida com a preservação dos recursos naturais. Já pontuações menores indicam uma visão antropocêntrica, voltada para a exploração dos recursos naturais (HAWCROFT; MILFONT, 2010).

Em 2000, após avaliação de trabalhos nas duas décadas que se passaram, os autores da escala propuseram algumas alterações. Silva Filho et al. (2009) comentam que algumas dessas alterações foram: a exclusão de termos "sexistas" em inglês e de um item especificamente do "controle do crescimento industrial"; a reflexão sobre os termos "ambiental" e "ecológico"; e, por último, de uma escala Likert com cinco itens, em vez de quatro.

Outra mudança foi o aumento das dimensões, ampliada de três para cinco. Foram incluídas questões sobre o isencionismo humano (a ideia que os seres humanos estão isentos de restrições da natureza); e também sobre a crise ecológica global. Assim a escala passa de doze para quinze questões, sendo oito pró e sete contra o novo paradigma ambiental (ALVES, 2013). Os itens atualizados são mostrados no Quadro 1.

Quadro 1 - Escala “Novo Paradigma Ecológico”

\begin{tabular}{|c|c|c|}
\hline Dimensões & Itens & Você concorda ou discorda que: \\
\hline \multirow{3}{*}{$\begin{array}{c}\text { I - Equilíbrio } \\
\text { da natureza }\end{array}$} & 3 & $\begin{array}{l}\text { Quando os seres humanos interferem na natureza, acontecem } \\
\text { frequentemente consequências desastrosas }\end{array}$ \\
\hline & 8 & $\begin{array}{l}\text { O equilíbrio natural é suficientemente estável para absorver os impactos das } \\
\text { nações industriais modernas }\end{array}$ \\
\hline & 13 & O equilíbrio natural é muito delicado e facilmente abalado \\
\hline \multirow{3}{*}{$\begin{array}{c}\text { II - Existência } \\
\text { de limites ao } \\
\text { crescimento }\end{array}$} & 1 & Nós estamos chegando ao número de pessoas que a Terra pode suportar \\
\hline & 6 & $\begin{array}{l}\text { A Terra tem riqueza em fontes naturais, nós temos que aprender a } \\
\text { desenvolvê-las }\end{array}$ \\
\hline & 11 & A Terra é uma espaçonave com espaço e fontes muito limitados \\
\hline \multirow{3}{*}{$\begin{array}{c}\text { III - } \\
\text { Antiantro- } \\
\text { pocentrismo }\end{array}$} & 2 & $\begin{array}{l}\text { Os seres humanos têm o direito de modificar o ambiente natural para } \\
\text { atender suas necessidades }\end{array}$ \\
\hline & 7 & Plantas e animais têm o direito de existir tanto quanto os humanos \\
\hline & 12 & O ser humano foi feito para reinar sobre a natureza \\
\hline \multirow{3}{*}{$\begin{array}{c}\text { IV - } \\
\text { Antiexcep- } \\
\text { cionalidade }\end{array}$} & 4 & A perspicácia humana assegurará que nós NÃO faremos a Terra inabitável \\
\hline & 9 & $\begin{array}{l}\text { Apesar de nossas habilidades especiais, os seres humanos ainda estão } \\
\text { sujeitos às leis da natureza }\end{array}$ \\
\hline & 14 & $\begin{array}{l}\text { Os seres humanos irão aprender o suficiente sobre como a natureza funciona } \\
\text { para serem capazes de controlá-la }\end{array}$ \\
\hline \multirow{3}{*}{$\begin{array}{l}\mathrm{V} \text { - Crise } \\
\text { ecológica }\end{array}$} & 5 & Os seres humanos estão abusando severamente do meio ambiente \\
\hline & 10 & $\begin{array}{l}\text { A chamada "crise ecológica" encarada pela humanidade tem sido } \\
\text { grandemente exagerada }\end{array}$ \\
\hline & 15 & $\begin{array}{l}\text { Se as coisas continuarem no curso atual, nós iremos brevemente } \\
\text { experimentar uma catástrofe ecológica maior }\end{array}$ \\
\hline
\end{tabular}

Fonte: Dunlap et al. (2000) (Adaptado)

A escala NEP teve estudos no Brasil que validaram sua consistência interna e a unidimensionalidade. (SILVA FILHO et al., 2009).

\subsubsection{Medida do Comportamento Ambiental}

Pato e Tamayo (2006) desenvolveram uma escala de comportamento ambiental baseado em estudos nos moldes das medidas de Karp e Kaiser. Nomeada de Escala de Comportamento Ecológico (ECE), a escala procura adaptar escalas estrangeiras à realidade sociocultural-ambiental brasileira. Após aplicação do teste em estudantes de educação média e universitária do Distrito Federal, Pato e Tamayo (2006) chegaram a ao total de vinte e nove itens considerados válidos e significativos. Levando em conta a extensão do questionário, as afirmativas foram consideradas de acordo com os 
quatro fatores significativos, ou grupos, que encontrados na pesquisa: Ativismo-Consumo, Economia de Água e Energia, Limpeza Urbana e Reciclagem.

O fator Ativismo-Consumo é caracterizado pelas ações relacionadas à preservação e conservação do meio ambiente, por meio de participação que envolva outras pessoas ou por meio de decisão de compras e de usos de produtos que podem ser considerados nocivos ou não ao meio ambiente. $O$ fator Economia de Água e Energia relaciona-se ao uso racional dos recursos naturais, apresentando comportamentos voltados para a economia (ou não desperdício) de água e de energia. O terceiro fator, Limpeza Urbana, diz respeito aos comportamentos de manutenção dos espaços públicos, associados ao tema lixo urbano. O último fator, Reciclagem, refere-se aos atos de separação de lixo doméstico, conforme seu tipo (PATO; TAMAYO, 2006).

Esses quatros fatores foram submetidos ao teste de consistência interna Alfa de Cronbach, e foi encontrado um valor de 0,80 , que é considerado um excelente valor. As cargas fatoriais também se mostraram satisfatórias. Desse modo, a Escala de Comportamento Ecológico (ECE) torna-se uma ferramenta válida e útil para a medição do comportamento ecológico no contexto brasileiro (PATO; TAMAYO, 2006).

\section{Metodologia}

O presente estudo é classificado como exploratório e descritivo. O caráter exploratório do estudo justifica-se pela ausência de pesquisas em relação ao assunto e a possibilidade de orientar os gestores educacionais do instituto em relação à educação ambiental. O caráter descritivo deve-se ao fato do presente estudo mensurar a consciência e o comportamento ambiental entre universitários de uma instituição federal através de um estudo comparativo entre diversas variáveis.

A pesquisa foi realizada com os universitários da instituição de ensino superior localizada em Maracanaú. Os cursos pesquisados foram o de Bacharelado em Ciências da Computação, Bacharelado em Engenharia Ambiental e Sanitária e Tecnologia em Manutenção Industrial.

A coleta de dados sobre a população foi realizada mediante questionário de pesquisa, aplicado em sala de aula, portanto, são dados primários. O instrumento é dividido em três partes. A primeira parte do questionário de pesquisa é constituída pela Escala NEP, descrita no referencial teórico. A Escala NEP utilizada nesta pesquisa é a escala revisada por Dunlap et al. (2000) e traduzida por Silva Filho et al. (2009), constituída de quinze questões em uma escala de concordância Likert de 1 (discordo totalmente) a 5 (concordo totalmente). Conforme indicada por Silva Filho et al. (2009), as questões 02, 04, 06, 08, 10, 12 e 14 são contrárias ao novo paradigma, ou seja, quanto maior a concordância a essas afirmativas, mais a negação ao novo paradigma. Por isso, as escalas dessas questões são invertidas, e assim visualizar o real grau de aderência ao novo paradigma ecológico.

A segunda parte do questionário investiga as características demográficas dos respondentes. $\mathrm{O}$ principal objetivo é conhecer o perfil da amostra estudada e a partir disto agrupar respondentes de acordo com variáveis de interesse, possibilitando comparações entre cursos, gêneros e educação ambiental.

A terceira parte investiga o comportamento e as práticas ambientais. Para medir o comportamento ambiental dos estudantes, foi utilizada a Escala de Comportamento Ecológico (ECE) desenvolvida por Pato e Tamayo (2006). Silva (2013) realizou uma pesquisa entre estudantes e funcionários do Instituto Federal do Ceará - Campus Fortaleza, de modo a investigar a relação entre percepção ambiental, comportamento e atitudes dessa população. Para isso, Silva (2013) utilizou dezesseis itens do questionário proposto por Pato e Tamayo (2006). Considerando a similaridade de população estudada e o objetivo da pesquisa, o presente estudo também utilizou os dezesseis itens escolhido por Silva (2013) para investigação do comportamento ambiental.

A escala das respostas consiste numa escala de frequência que varia de 1 a 6 , em que a opção " 1 " significa que o respondente nunca pratica tal ação, e a opção " 6 " mostra que o respondente sempre pratica a ação. Da mesma forma que a Escala NEP, o questionário de comportamento ambiental apresenta questões que uma maior frequência indica menor atitude pró-ambiental. Assim, a escala dessas questões será invertida para refletir o real comportamento ambiental.

REGET - V. 20, n. 1, jan.- abr. 2016, p.334-350 


\subsection{Método de Coleta e Análise dos Dados}

A pesquisa foi aplicada nas últiimas semanas de novembro de 2013 nas salas de aula, com o auxílio dos professores e coordenadores de curso. Outros dez alunos responderam o questionário por meio eletrônico, através da ferramenta Google Docs. O total de questionários válidos, distribuído por curso, está demonstrado no Quadro 2.

De acordo com a Coordenadoria de Controle Acadêmico da instituição de ensino e dos coordenadores de curso, o total de alunos iniciantes e concludentes dos cursos pesquisados somam 185. No presente estudo, consideram-se iniciantes os estudantes dos dois primeiros semestres de cada curso. Por sua vez, os concludentes são aqueles que se encontram no penúltimo e último semestre.

Quadro 2 - Respondentes por curso e semestre

\begin{tabular}{|ccc|}
\hline CURSO & TIPO & RESPONDENTES \\
\hline \multirow{2}{*}{ Ciências da Computação } & Iniciantes & 33 \\
\cline { 2 - 3 } & Concludentes & 13 \\
\hline \multirow{2}{*}{ Engenharia Ambiental e Sanitária } & Iniciantes & 26 \\
\cline { 2 - 3 } & Concludentes & 17 \\
\cline { 2 - 3 } Tecnólogo em Manutenção Industrial & Iniciantes & 26 \\
\cline { 2 - 3 } & Concludentes & 85 \\
\hline TOTAL & Iniciantes & 38 \\
\hline TOTAL & Concludentes & 123 \\
\hline TOTAL & Iniciantes e Concludentes \\
\hline
\end{tabular}

Fonte: Dados da pesquisa

Com base no Quadro 2, observa-se que o número de estudantes concludentes é significantemente superior ao número de concludentes. No entanto, os motivos dessa discrepância entre as extremidades podem ser explicadas pela desistência (evasão) ou reprovação (retenção) de estudantes ou longo do curso, fatos que reduzem o número de alunos formandos.

Os dados quantitativos foram tabulados em uma planilha eletrônica do Microsoft Excel 2010 e a análise estatística foi realizada com o auxílio do pacote Statistical Package for The Social Sciences (SPSS) versão 21. Foram utilizadas técnicas de estatística descritiva para demonstração da base de dados, tais como médias, distribuição de frequência, teste de normalidade e divisão da distribuição em percentis. Adicionalmente, também foram utilizadas técnicas de inferência estatísticas, como teste $t$ para amostras independentes e a análise de variância ANOVA.

O teste $t$ para amostras independentes foi realizado quando a comparação de médias ocorreu com apenas dois grupos; no caso de comparações com três ou mais grupos, foi usada análise de variância ANOVA. O intervalo de confiança utilizado em todas as análises foi de $95 \%$ e nível de significância de $5 \%$.

\section{Análise dos Resultados}

Em termos de dados demográficos, a amostra pode ser descrita como apresentando uma média de idade dos respondentes de 22,3 anos. O perfil jovem encontrado pode ser explicado pela proporção de respondentes do tipo iniciantes $(69,1 \%)$ em relação aos concludentes $(30,9 \%)$. Com relação ao gênero, observa-se que $68,3 \%$ dos respondentes são do sexo masculino e $31,7 \%$ são do sexo feminino. A renda familiar dos entrevistados ficou distribuída da seguinte forma: 7,32\% têm renda de até $R \$ 700 ; 21,95 \%$ entre $R \$ 700$ e $R \$ 1.400 ; 27,64 \%$ entre $R \$ 1.400$ e $R \$ 2.400 ; 18,70 \%$ entre $R \$ 2.400$ e $R \$$ $3.800 ; 13,01 \%$ entre $\mathrm{R} \$ 3.800$ e $\mathrm{R} \$ 7.000$; e $11,38 \%$ mais de 7.000 . Por fim, o percentual de estudantes que estudaram conteúdos de educação ambiental antes do ingresso no nível superior foi de 51,2 e os 
que não estudaram foi de $48,8 \%$, o que demonstra que a sustentabilidade não é discutida nos ensinos básicos e intermediários. Apesar do equilíbrio em relação à amostra, quando se investiga a proporção entre os cursos, o quadro se altera: o curso de Engenharia Ambiental possui expressivos $67,44 \%$ de estudantes que tiveram contato com disciplinas abordagem sustentável; inversamente, no curso de Ciência da Computação, a maioria (63,04\%) não estudou o tema antes do ingresso no nível superior.

\subsection{Avaliação da Consciência Ambiental}

\subsubsection{Definição do Teste de Consciência Ambiental}

Para avaliar o nível de consciência ambiental dos estudantes universitários, foi utilizada a Escala NEP. O primeiro passo, porém, foi testar a confiabilidade interna da escala através do Alfa de Cronbach. O valor calculado foi de 0,619 e o Alfa de Cronbach para valores padronizados é 0,637, valor considerado como aceitável para pesquisas exploratórias (Hair et al.,2005).

O segundo passo foi testar se as médias calculadas do questionário NEP seguem uma distribuição normal. Com o auxílio do da ferramenta SPSS, utilizando o teste de Kolmogorov-Smirnov, encontrouse $\mathrm{D}(123)=0,06$, com $\mathrm{p}=0,200$. De acordo com Field (2009), quando o valor de "p" para testes de normalidade for superior ao nível significância (5\%), conclui-se que os dados da amostra não diferem significativamente de uma amostra normal. Assim, admite-se que a média segue uma distribuição normal. Verificou-se também que as médias de consciência ambiental por curso e entre gêneros, ambas apresentando distribuição normal $(p>0,05)$.

\subsubsection{Resultados do Teste de Consciência Ambiental}

A média obtida entre todos os estudantes pesquisados foi de 3,76 e desvio padrão de 0,442 , sendo considerada uma medida da consciência ambiental. Tal medida, superior a 3, mostra ser uma média relativamente alta, indicando uma tendência ambiental favorável (Battistela et al., 2011). A menor média encontrada foi de 2,53, no curso de Ciências da Computação, e a maior foi de 4,67, no curso de Engenharia Ambiental.

O passo seguinte foi comparar as médias entre os três cursos, que apresentaram distribuição normal, justificando o uso do teste ANOVA. De acordo com Field (2009), no teste ANOVA, níveis de significância $\mathrm{p}>0,05$ (significância escolhida do estudo) mostram que existe uma probabilidade maior que $5 \%$ de os valores terem ocorrido por acaso. Encontrou-se um nível de significância $p=0,585$, número superior ao nível de significância tolerado, denotando que, no que diz respeito à consciência ambiental, não há diferenças significativas entre os cursos.

$\mathrm{O}$ estudo também pesquisou a diferença entre gêneros. A média de consciência entre os respondentes do sexo masculino foi 3,71 e desvio padrão 0,441. Já a média do sexo feminino foi 3,88 e desvio padrão 0,430. Antes de fazer alguma conclusão, é necessário verificar se a diferença entre as médias é significativa. Realizou-se o Teste de Levene, que verifica a igualdade de variância entre grupos, encontrando-se um valor de significância $p=0,62$. De acordo com Field (2009), valores acima do nível de significância $(\mathrm{p}>0,05)$ indicam que a diferença entre as variâncias é zero. Assim, pode-se afirmar que as variâncias entre os grupos são semelhantes. Com base nisso, aplicou-se o teste t para amostras independentes. $O$ resultado obtido foi [t(121) $=-1,987 ; p=0,049]$. Nesse caso, pode-se afirmar que as médias possuem diferenças suficientemente significativas entre si, demonstrando que a média de consciência ambiental do gênero feminino é maior que a média do gênero masculino.

A análise seguinte consistiu em comparar a consciência ambiental entre os estudantes iniciantes e concludentes. A média dos iniciantes foi de 3,764, com desvio padrão de 0,427. Os concludentes tiveram média de 3,777 e desvio padrão de 0,483. Aplicando o teste t para amostras independentes, e assumindo que as variâncias são iguais (Teste de Levene: $\mathrm{p}=0,517$ ), foi concluído que não há diferenças significativas entre os universitários ingressos e os que egressos do curso $[t(121)=0,23 ; p=$ 0,982].

Finalmente, a última análise concernente à consciência ambiental relacionou-se ao contato que os estudantes tiveram com educação ambiental antes de iniciar o curso superior. O grupo 1 foi composto 
pelos universitários que estudaram conteúdos de sustentabilidade antes da faculdade, e o grupo 2 foi formado pelos estudantes de situação contrário.

A média do grupo 1 ("Sim") foi de 3,84 e desvio padrão de 0,44. O grupo 2 ("Não") teve média de 3,68 e desvio padrão de 0,43 . Aplicando o teste t para amostras independentes e assumindo variâncias iguais (Teste de Levene $\mathrm{p}=0,517$ ), foi constatada que existem diferenças significativas entre as médias dos dois grupos $[t(121)=2,086 ; p=0,039]$, portanto, a consciência ambiental é maior entre os universitários que estudaram sustentabilidade antes de iniciar o ensino superior.

\subsection{Avaliação do Comportamento Ambiental}

\subsubsection{Definição do Teste de Comportamento Ambiental}

A confiabilidade do teste de comportamento foi comprovada por meio da verificação do Alfa de Cronbach. O valor do Alfa para a escala foi 0,735. Para valores de escala padronizados, o Alfa de Cronbach é 0,739, que é considerado bom para medidas de confiança. Em seguida, foi verificado se a amostra segue uma distribuição normal. A normalidade da amostra foi comprovada por meio do teste de Kolmogorov-Smirnov, $[\mathrm{d}(123)=0,05 ; \mathrm{p}=0,200]$. A segunda análise a ser considerada foi a comparação entre as médias de comportamento ambiental por curso. Novamente, comprovou-se a normalidade da população, dessa vez por cursos $(p=0,200)$.

A avaliação do comportamento ambiental entre gêneros constitui a terceira etapa da pesquisa de comportamento. $\mathrm{O}$ teste de normalidade aplicado aos dois grupos concluiu que o comportamento ambiental, dividido por gênero, também segue uma distribuição normal ( $p>0,05)$. $O$ comportamento ambiental entre ingressos e egresso foi outro objeto de comparação no presente estudo. $O$ teste Kolmogorov-Smirnov atesta mais uma vez a normalidade das distribuições de ingresso e egressos $(\mathrm{p}=$ 0,200). Finalmente, outra relação estudada foi entre a consciência ambiental entre os estudantes que tiveram alguma forma de educação ambiental antes de iniciar o curso superior e os estudantes que não tiveram nenhum contato. $\mathrm{O}$ teste de normalidade a que os grupos foram submetidos indicaram que as distribuições deles possuem normalidade $(\mathrm{p}=0,200)$.

\subsubsection{Análise do Comportamento Ambiental}

A média de comportamento obtida entre os estudantes foi de 3,771 e desvio padrão de 0,621 , sendo considerada uma medida de comportamento ambiental. A menor média encontrada foi de 1,875, no curso de Ciências da Computação, e a maior foi de 5,25, no curso de Engenharia Ambiental.

A próxima comparação realizada foi entre as médias dos cursos. A menor média apresentada ocorre no curso de Tecnologia em Manutenção Industrial (média $=3,61$; desvio-padrão $=0,589$ ) e a maior média encontra-se no curso de Engenharia Ambiental (média $=4,028$; desvio padrão=0,657). A comparação entre cursos, por meio do teste Oneway ANOVA, evidenciou que as médias diferem significativamente entre si $(p=0,003<0,05)$. A partir desse resultado, pode-se concluir que, no que diz respeito a comportamento ambiental, há diferenças significativas entre os cursos. No entanto, Field (2009, p.299) alerta que, "embora a ANOVA nos informe se a manipulação experimental teve sucesso, ela não nos fornece informações específicas sobre quais grupos foram afetados".

Para detectar qual(is) grupo(s) possuem diferenças, Field (2009) aconselha a realização dos procedimentos Post Hoc, usados, conforme explica o autor, quando não há previsões específicas a priori sobre os dados coletados, e o interesse é verificar a existência de quaisquer possíveis diferenças entre médias. O procedimento Post Hoc foi adotado neste estudo, sendo escolhido três tipos de testes: Tukey, REGWQ e Games-Howell. Os testes foram realizados de modo que cada grupo (I) tivesse sua média comparada às outras (J), e o nível de significância entre essas diferenças indicado. Para execução do teste, adotou-se que o curso de Ciências da Computação como o grupo 1; Engenharia Ambiental como o grupo 2; e Tecnologia em Manutenção Industrial como o grupo 3.

Pelo quadro obtido, nota-se que o nível de significância das comparações entre o grupo 1 e 3 é $p=$ 0,963 no teste Tukey e $p=0,959$ no teste Games Howell e $p=0,948$ no teste Dunnet. Como o nível de significância é $\mathrm{p}=0,05$, conclui-se que não existem diferenças significativas entre as médias desses grupos. Por outro lado, quando se comparam as médias do grupo 2 com os grupos 1 e 3, é possível observar que os níveis de significância são $\mathrm{p}=0,009$ no teste Tukey; no teste de Games-Howell, a

REGET - V. 20, n. 1, jan.- abr. 2016, p.334-350 
significância entre o grupo 2 e o grupo 1 é $p=0,011(<0,05)$ e entre o grupo 2 e o grupo 3 é $p=0,013$ (< 0,05). Portanto, os resultados obtidos com a análise de variância (ANOVA) em conjunto com os testes Post Hoc permitem inferir que a média de comportamento ambiental dos estudantes de Engenharia Ambiental é significativamente diferente à média dos outros cursos.

Tabela 1 - Diferenças de Comportamento Ambiental entre os Cursos

\begin{tabular}{|c|c|c|c|c|c|c|c|}
\hline \multirow{2}{*}{$\begin{array}{c}\text { Variável } \\
\text { dependente: MÉDIA }\end{array}$} & \multirow{2}{*}{$\begin{array}{c}\text { (I) } \\
\text { Cursos }\end{array}$} & \multirow{2}{*}{$\begin{array}{c}(\mathrm{J}) \\
\text { Cursos }\end{array}$} & \multirow{2}{*}{$\begin{array}{l}\text { Diferença } \\
\text { média (I-J) }\end{array}$} & \multirow{2}{*}{$\begin{array}{c}\text { Modelo } \\
\text { padrão }\end{array}$} & \multirow[t]{2}{*}{ Sig. } & \multicolumn{2}{|c|}{$\begin{array}{c}\text { Intervalo de confiança } \\
95 \% \\
\end{array}$} \\
\hline & & & & & & $\begin{array}{c}\text { Limite } \\
\text { inferior }\end{array}$ & $\begin{array}{c}\text { Limite } \\
\text { superior }\end{array}$ \\
\hline \multirow{6}{*}{ Tukey HSD } & \multirow{2}{*}{1} & 2 &,$- 378^{*}$ & ,127 & ,009 &,- 679 &,- 078 \\
\hline & & 3 & ,036 & ,135 & ,963 &,- 285 & ,356 \\
\hline & \multirow{2}{*}{2} & 1 & $378^{*}$ & ,127 & ,009 & ,078 & ,679 \\
\hline & & 3 & $414^{*}$ & ,137 & ,009 & ,089 & ,739 \\
\hline & \multirow{2}{*}{3} & 1 &,- 036 & ,135 & ,963 &,- 356 & ,285 \\
\hline & & 2 &,$- 414^{*}$ & 137 & ,009 &,- 739 &,- 089 \\
\hline \multirow{6}{*}{ Games-Howell } & \multirow{2}{*}{1} & 2 &,$- 378^{*}$ & ,128 & ,011 &,- 684 &,- 073 \\
\hline & & 3 &, 036 & ,129 & ,959 &,- 273 & ,344 \\
\hline & \multirow{2}{*}{2} & 1 & $378^{*}$ & ,128 & ,011 & ,073 & ,684 \\
\hline & & 3 & $414^{*}$ & ,142 & ,013 & ,073 & ,754 \\
\hline & \multirow{2}{*}{3} & 1 &,- 036 & ,129 & ,959 &,- 344 & ,273 \\
\hline & & 2 &,$- 414^{*}$ & ,142 & ,013 &,- 754 &,- 073 \\
\hline Dunnett ${ }^{t}$ & \multicolumn{2}{|c|}{13} & ,036 & 135 & ,948 &,- 265 & ,336 \\
\hline$(2 \text { lados })^{b}$ & 2 & 3 &, $414^{*}$ & 137 & ,006 & ,108 & ,719 \\
\hline
\end{tabular}

Fonte: Dados da pesquisa

A terceira análise quanto ao comportamento é a comparação entre gêneros. A média entre os respondentes do sexo masculino foi 3,59 e desvio padrão de 0,53. A média calculada entre as entrevistadas do sexo feminino foi 4,16 e desvio padrão 0,62. Como os dois grupos possuem uma distribuição normal, aplicou-se o teste t para amostras independentes. O Teste de Levene aponta que as variâncias entre os grupos são homogêneas $(p=0,186)$. Assumindo essa condição, verifica-se que as médias de comportamento das amostras são significantemente diferentes entre si $[d(121)=-5,207 ; p=$ 0,0000], demonstrando que o comportamento ambiental das mulheres é significantemente superior ao dos homens.

Adicionalmente, buscou-se comparar as médias entre estudantes iniciantes e concludentes. A média encontrada entre os ingressantes foi 3,64 e desvio padrão 0,61. Os universitários egressos, por sua vez, obtiveram uma média de 4,06 e desvio padrão 0,55 . Assumindo a condição de normalidade anteriormente explicada, aplicou-se o teste $t$ de amostras independentes. Assumindo que as variâncias são homogêneas (Teste de Levene: $\mathrm{p}=0,519>0,05$ ), o teste aponta que as médias entre os estudantes iniciantes e concludentes são significantemente diferentes entre si $[d(121)=3,663 ; p=0,000]$. Em outras palavras, o nível de comportamento ambiental entre os estudantes egressos é superior aos estudantes iniciantes.

Por fim, as médias estudadas foram agrupadas de acordo com a variável "Educação Ambiental", pertencente ao questionário. O primeiro grupo abrange os que responderam "Sim", ou seja, estudaram algum conteúdo de sustentabilidade antes de ingressar no nível superior. O segundo grupo corresponde aos que responderam "Não", que significa que não estudaram o tema na sua educação formal pré-universitária. A média do grupo "Sim" foi de 3,92 e desvio padrão de 0,64. A média do grupo "Não" foi de 3,61 e desvio padrão de 0,55. Aplicando-se o teste t para amostras independentes, o Teste de Levene apontou nível de significância $p=0,516$, o que indica que as variâncias entre os grupos são semelhantes. No caso de variâncias semelhantes, constatou-se que as 
médias possuem diferenças significativas entre si $[d(121)=2,798 ; p=0,006)$. Dessa forma, pode-se concluir que aqueles que estudaram sustentabilidade antes de iniciar o ensino superior apresenta comportamento ambiental significativamente superior aos que não tiveram contato com o tema.

\section{Considerações finais}

Este estudo teve como objetivo mensurar o nível de consciência ambiental e comportamento ambiental entre estudantes universitários de uma instituição tecnológica. Além disso, foram feitas comparações de médias entre grupos, de acordo com uma variável independente escolhida.

Os estudos da consciência ambiental resultaram em uma média geral de 3,76, o que representa uma média relativamente alta. Battistela et al. (2011), em uma pesquisa com professores universitários utilizando a Escala NEP, encontrou uma média de 3,66; Alves (2013), que pesquisou a consciência ambiental em estudantes do Instituto Federal do Rio Grande do Sul também utilizando a Escala NEP, achou uma média de 3,89. Levando em conta tais pesquisas, a média geral dos estudantes universitário demonstra um valor favorável.

Os estudos sobre a consciência ambiental apontaram também que as médias entre os cursos não diferem significativamente uma da outra; tampouco o fato de ser iniciante ou concludente também não representou diferença significativa. Nesse sentido, os cursos superiores pesquisados não possuem influência relevante no que diz respeito à consciência, às crenças individuais sobre o ambiente.

Por outro lado, o estudo sobre gêneros aponta que as mulheres possuem uma média de consciência ambiental superior aos dos homens. Essa constatação vai ao encontro de outras pesquisas, como Battistela et al. (2011), que investigou a consciência ambiental entre professores universitários também utilizando a escala NEP. Interessante comentar que, embora o número de mulheres esteja concentrado no curso de Engenharia Ambiental, isso não afetou média de consciência ambiental entre cursos.

Diferenças de consciência também foram encontradas no estudo sobre educação ambiental: estudantes que tiveram contato com conteúdos sobre sustentabilidade antes de iniciar o ensino superior obtiveram média de consciência ambiental superior à dos outros grupos. Tal comprovação pode sugerir o efeito positivo do estudo de questões ambientais nos ensinos básico e intermediário. Alves (2013), por sua vez, não observou essa relação ao medir a consciência ambiental de estudantes do Instituto Federal do Rio Grande do Sul.

O estudo sobre comportamento apresentou nos resultados mais diferenças significativas entre grupos do que os resultados da consciência ambiental. No caso da comparação entre cursos, a Engenharia Ambiental apresentou diferença significativa comparada aos outros dois cursos. A semelhança entre as médias de consciência entre cursos e a diferença entre médias no comportamento (no caso, Engenharia Ambiental ser superior) parecem indicar que esta possui caráter mais moldável do que aquela. $O$ fato do curso de Engenharia Ambiental apresentar média superior a outros cursos pode ser um possível sinal de que a vivência das disciplinas possa afetar comportamento, embora não interfira nas outras dimensões da consciência ambiental. Pesquisas posteriores mais detalhadas podem ser feitas para descobrir possíveis influências no comportamento ambientalmente correto aplicado aos cursos.

Quando avaliada na questão do gênero, o comportamento, consoante à consciência, também aponta média significantemente superior para o grupo feminino. O resultado encontra apoio em outras pesquisas (Battistela et. al., 2011), que também indicam que as mulheres apresentam maior comportamento ambientalmente correto.

A comparação de comportamento entre iniciantes e concludentes apresentou interessante resultado: enquanto que a consciência ambiental não é afetada pela vida universitária, o comportamento ambiental apresenta uma média significativamente maior nos alunos concludentes no que dos iniciantes. Tal constatação, realizada em relação a todos os cursos, pode ser posteriormente investigada para cada curso de forma individual, verificando se é uma situação comum aos três cursos ou se há concentração em algum curso específico.

REGET - V. 20, n. 1, jan.- abr. 2016, p.334-350 
Em resumo, pode-se dizer que as maiores médias de níveis de consciência ambiental são encontradas no gênero feminino. No caso do comportamento ambiental, as pessoas que possuem maiores ações ambientalmente corretas são as que estudam Engenharia Ambiental, concludentes, do gênero feminino e que tiveram contato com disciplinas de Educação Ambiental antes de iniciar a faculdade. Os resultados alcançados nesta pesquisa podem fornecer insumos para futuras pesquisadas mais detalhadas sobre fatores que afetam a consciência ambiental e o comportamento ambiental. A nível pedagógico, a instituição de ensino estudada pode direcionar esforços para incentivos de práticas sustentáveis nos cursos, tendo em vista que o comportamento ambiental apresenta diferenças entre cursos e semestres. A evidência de que os homens possuem menos ações ambientalmente corretas que as mulheres pode servir de auxílio no sentido de orientar esforços para esse público, haja vista no ambiente universitário o gênero masculino representar mais de $68 \%$ da população.

Uma das limitações do estudo refere-se à sua amostra. A pesquisa limitou-se a apenas um campus, fato também influenciou o valor de Alfa de Cronbach em 0,63; um estudo mais abrangente pode ser realizado com outros campi. O estudo pode ser estendido também às outras modalidades de ensino existentes na instituição, a saber: ensino técnico tradicional, ensino técnico à distância (EAD) e ensino do Programa Nacional de Acesso ao Ensino Técnico e Emprego (PRONATEC).

Outra limitação refere-se ao modelo de análise adotado: apesar de possível a comparação entre as médias, não é possível indicar fatores que contribuam para o resultado encontrado. Como sugestão, uma análise dos fatores pode ser estudada.

A pesquisa indicou que quase metade dos alunos nunca teve contato com educação ambiental antes de iniciar a faculdade, fato que demonstra que o ensino ambiental ainda não é prática difundida na educação formal básica e intermediária. Dessa forma, as IES se tornam um meio estratégico de conscientização ambiental, não importando a área de estudo de cada disciplina, tendo em visto que a educação ambiental é conceito amplo e se insere de forma transversal nas mais variadas disciplinas.

\section{Referências}

ALVES, N.B. A Consciência ambiental dos jovens: uma pesquisa com estudantes do ensino médio técnico e superior tecnológico.(Dissertação) . Porto Alegre. Universidade Federal do Rio Grande do Sul, 2013.2 Disponível em:<http://www.lume.ufrgs.br/bitstream/handle/10183/76195/000893539.pdf?sequence=1>. Acesso em: 13/10/2013.

BARBIERI, J.C. Desenvolvimento e Meio Ambiente: as estratégias de mudanças da Agenda 21. 8 ed. Petrópolis, RJ. Vozes, 2007.

BARBIERI, J.C.; SILVA, DIRCEU. Desenvolvimento Sustentável e Educação Ambiental: Uma Trajetória Comum com muitos Desafios. Revista de Administração Mackenzie[Intenet] 2011 [Acesso 02/11/2013];12(3): p.51-82. http://www.scielo.br/pdf/ram/v12n3/a04v12n3.pdf..

BARBIERI, J.C; CAJAZEIRAS, J. E. R. Responsabilidade Social Empresarial e Empresa Sustentável: da teoria à prática. São Paulo: Editora Saraiva, 2009.

BATTISTELA, L.F.; VELTER, A.N.; GROHMANN, M.Z.; CASASOLA, F.P. Aplicação da Escala-NEP para mensuração da consciência ecológica de professores universitários: perfis e implicações para estudos futuros. Revista Desenvolvimento em Questão[Internet] 2011[Acesso 02/11/2013];10(9):p.207-238. Disponível em: http://www.spell.org.br/documentos/download/7126.

BEDANTE, G. N; SLONGO, L. A. O comportamento de consumo sustentável e suas relações com a consciência ambiental e a intenção de compra de produtos ecologicamente embalados [Internet] (Dissertação). Porto Alegre: Escola de Administração/UFRGS, 2007 [Acesso em 03/11/2013] 
[Internet] 2004novembro 05-07; Porto Alegre, Brasil. 2004[Acesso em: 05/10/2013]. Disponível em: https://www.lume.ufrgs.br/bitstream/handle/10183/3904/000450535.pdf?sequence=1

República Federativa do Brasil.. Lei no 9.795/1999. “Dispõe sobre a educação ambiental, institui a Política Nacional de Educação Ambiental e dá outras providências". Brasília (Brasil).Disponível em: <http://www.planalto.gov.br/ccivil_03/leis/19795.htm>. Acesso em: 02/10/2013.

BUTZKE, I.C.; PEREIRA, G.R.; NOEBAUR, D. Sugestões de indicadores para avaliação do desempenho das atividades educativas do sistema de gestão ambiental. Revista Eletrônica do Mestrado em Educação Ambiental, Furb,2001,.

CHAWLA, L.; CUSHING, D.F. Education for strategical environmental behavior. Environmental Education Research [Internet] 2007[Acesso em: 02/11/2013];v.13(4)p.437-452. Disponível em: http://www.colorado.edu/cye/sites/default/files/attached-

files/Chawla\%2C\%20L.\%20\%26\%20Flanders\%20Cushing\%2C\%20D.\%20\%282007\%29.\%20Educatio n\%20for\%20strategic\%20environmental\%20behavior.Environmental\%20Education\%20Research\%2 C\%2013\%284\%29\%2C\%20437-452..pdf.

CZYKIEL, R. Sustentabilidade a flor da pele: a educação como agente de transformação de atitudes. Revista Sustentabilidade: Resultados de pesquisas do PPGA/EA/UFRGS. Porto Alegre: Grupos de Pesquisa em Sustentabilidade e Inovação - GPS, 2013.

DEMAJOROVIC, J.; SILVA, H.C.O. Formação Interdisciplinar e sustentabilidade em cursos de Administração: desafios e perspectivas. Revista de Administração Mackenzie [Internet]. 2012[Acesso em: 21/10/2013];v.13(5):p.39-64. Disponível em: http://www.scielo.br/pdf/ram/v13n5/v13n5a03.pdf.

DIAMANTOPOULOS, A.; SCHLEGELMILCH, B. B.; SINKOVICS, R.R.; BOHLEN, G. M. Can sociodemographics still play a role in profiling green consumers? A review of the evidence and an empirical investigation. Journal of Business Research, 2003;v.56:p.465-480.

DIAS, R. Marketing Ambiental: ética, responsabilidade social e competitividade nos negócios. São Paulo: Atlas, 2008.

DUNLAP, R.E.; VAN LIERE, K.D.; MERTIG, A.G.; JONES, R.S. Measuring Endorsement of the New Ecological Paradigm: A Revised NEP Scale. Journal of Social Issues[Internet]. 2000 [Acesso em 31/10/2013];v.56,n.3:p.425-442. Disponível em: http://citeseerx.ist.psu.edu/viewdoc/download?doi=10.1.1.397.3294\&rep=rep1\&type=pdf

FIELD, A. Descobrindo a estatística usando o SPSS. Tradução: Lori Viali. $2^{\underline{a}}$ ed. Porto Alegre: Artmed, 2009.

FRANCO, M. A. R. Planejamento Ambiental para a cidade sustentável. 2ª ed. São Paulo, SP: Annablume; Fapesp, 2008.

HAIR JR, J.F.; ANDERSON, R.E; TATHAM, R.L.; BLACK, W.C. Análise Multivariada de dados. 5a ed. Porto Alegre: Bookman, 2005.

HAWCROFT, L. J.; MILFONT, T. L. The use (and abuse) of the new environmental paradigm scale over the last 30 years: A meta-analysis. Journal of Environmental Psychology, 2010;v.30:p.143-158.

HENDERSON, H.; SETHI, S. Mercado Ético: a força do novo paradigma empresarial. São Paulo, SP: Cultrix, 2006. 
JACOBI, P.R.; RAUFLLET, E.; ARRUDA, M.P. Educação para a sustentabilidade nos cursos de educação: reflexão sobre paradigmas e práticas. Revista de Administração Mackenzie [Internet] 2011[Acesso em: 31/10/2013];v.12(3), , Edição Especial. Disponível em: http://www.producao.usp.br/bitstream/handle/BDPI/6422/art_JACOBI_Educacao_para_a_sustenta bilidade_nos_cursos_de_2011.pdf?sequence=1\&isAllowed=y

LIMA, A.V. Os portugueses e o ambiente. In: Curso de Verão da Ericeira. Lisboa, 2009. Anais...Lisboa, Portugal. Disponível em: <http://www.icea.pt/Actas/21_15h30m_Aida\%20Valadas.pdf >. Acesso em: 09/11/2013.

LOURES, R.C. da R. Sustentabilidade XXI: educar e inovar sob uma nova consciência. São Paulo: Editora Gente, 2009.

MARINHO, A.M.S. A educação ambiental e o desafio da interdisciplinaridade. [Internet]. (Dissertação) Pontíficia Universidade Católica de Minas Gerais, 2004 [Acesso em: 06/11/2013). Disponível em: <http://www.biblioteca.pucminas.br/teses/Educacao_MarinhoAM_1.pdf>.

MAZZA, INGRID; OLIVEIRA, L.G.L.; RAMOS, R.R.; COSTA, F.J. Importância percebida e intenções de envolvimento com a gestão social e ambiental: uma análise comparativa junto a estudantes do curso de administração. Revista Contextus [Internet], 2011[Acesso em: 30/10/2013];v.9, n. 2: p. 722. Disponível em: http://www.contextus.ufc.br/index.php/contextus/article/view/250/122

Ministério da Educação.. Catálogo Nacional dos Cursos Superiores de Tecnologia [Internet] 2010 [Acesso em: 31/10/2013]. Brasília (Brasil)Disponível em: $<$ http://portal.mec.gov.br/index.php?Itemid=\&gid=5362\&option=com_docman\&task=doc_downloa d.>. Acesso em: 25/11/2013.

NASCIMENTO, L.F.; LEMOS, A.; MELLO, M. Gestão socioambiental estratégica. Porto Alegre: Bookman, 2008.

NASCIMENTO, L.F. Gestão Ambiental e Sustentabilidade. Brasília: CAPES: UAB, 2012.
ONU. Agenda 21. : CONFERÊNCIA DAS NAÇÕES UNIDAS SOBRE O MEIO AMBIENTE E DESENVOLVIMENTO, 2012 [Acesso em: 05/11/2013]. Disponível em: $<$ http://www.onu.org.br/rio20/img/2012/01/agenda21.pdf >.

ONU. COMISSÃO MUNDIAL SOBRE MEIO AMBIENTE E DESENVOLVIMENTO (CNUMAD). Nosso futuro Comum. São Paulo: Fundação Getúlio Vargas, 1991.

PATO, C.M.L.; TAMAYO, A. A Escala de Comportamento Ecológico: desenvolvimento e validação de um instrumento de medida. Revista Estudos de Psicologia [Internet], 2006 [Acesso em: 02/11/2013] ;v.11(3):p.289-296. Disponível em: http://www.scielo.br/pdf/epsic/v11n3/06.pdf

RICKINSON, Mark. Learners and Learning in Environmental Education: a critical review of the evidence. Environmental Education Research [Internet]. 2001 [Acesso em: 31/10/2013];v. 7(3).

ROPER, Organization. The environment: public attitudes and individual behavior.2011. Disponível em:

$<$ http://www.scjohnson.com/Libraries/Download_Documents/SCJ_and_GfK_Roper_Green_Gauge. sflb.ashx>. Acesso em: 07/11/2013.

SCHLEGELMILCH, B. B; BOHLEN, G. M; DIAMANTOPOUlOS, A. The link between green purchasing decisions and measures of environmental consciousness. European Journal of 
Marketing [Internet] 1996[Acesso em: 06/11/2013] ;v. 30(5):p. 35-55,. Disponível em: http://citeseerx.ist.psu.edu/viewdoc/download?doi=10.1.1.457.8846\&rep=rep1\&type=pdf

SEIFFERT, M. E. B. Gestão Ambiental: instrumentos, esferas de ação e educação ambiental. São Paulo, SP: Atlas, 2007.

SILVA FILHO, J. C. L. da; TOCHETTO, M. R. L.; GRAVONSKI I; TORRES F. S. de; ARAUJO, N. R. S. Análise Comparativa do Novo Paradigma Ecológico em dois Estados Brasileiros: A Gestão Ambiental além do Mercado e do Estado. Revista Gestão.Org [Internet], 2009[Acesso em: 20/10/2013);v. 7(1):p.84-101. Disponível em: http://www.revista.ufpe.br/gestaoorg/index.php/gestao/article/viewFile/100/89

SOUZA, M. T. S. de; RIBEIRO, H. C. M.; MACHADO JUNIOR, C; CORREA, R. Perfil e Evolução da Pesquisa em SustentabilidadeAmbiental:Uma Análise Bibliométrica. In: Enanpad, 2011.

UNESCO [Internet]. Década das Nações Unidas da Educação para o Desenvolvimento Sustentável, 2005[Acesso em:07/11/2013].

Disponível em:<http://unesdoc.unesco.org/images/0013/001399/139937por.pdf>..

VENZKE, C.S.; NASCIMENTO, L.F.M. Caminhos e desafios para a inserção da sustentabilidade socioambiental na formação do administrador brasileiro. Revista de Administração Mackenzie[Internet]. 2013[Acesso em: 26/10/2013];v. 14[3]: p.26-54. Disponível: http://www.spell.org.br/documentos/ver/10390/caminhos-e-desafios-para-a-insercao-dasustentabilidade-socioambiental-na-formacao-do-administrador-brasileiro 